\title{
RESPONSABILIDADE CIVIL E ÉTICA DAS VIRTUDES A PARTIR DE ALASDAIR MACINTYRE
}

\section{Pastora do Socorro Teixeira Leal ${ }^{1}$ \\ Alexandre Pereira Bonna ${ }^{2}$}

\section{Resumo}

Apresenta o conceito de virtude para Alasdair MacIntyre em sua obra "After Virtue" (1981). Desenvolve os problemas de desordem moral presentes na modernidade. Aborda fundamentos para o resgate da ética das virtudes em face do atomismo e da fragmentação do indivíduo na modernidade. Aprofunda os três estágios da vida virtuosa para Alasdair MacIntyre, calcados nas práticas, na unidade narrativa da vida humana e na tradição. Traça os contornos dogmáticos da responsabilidade civil. Tem por objetivo refletir sobre o impacto da ética das virtudes de Alasdair MacIntyre no instituto da responsabilidade civil, em especial no salto qualitativo na fixação do "quantum" indenizatório, desenvolvimento de novas funções da responsabilidade civil e no alargamento da responsabilidade objetiva. Conclui que a luta contra a patrimonialização do direito deve ser uma tarefa diuturna de todos os profissionais do direito, os quais podem qualificar esse objetivo a partir da fundamentação da ética das virtudes no campo da responsabilidade civil.

Palavras-chave: responsabilidade civil; ética; virtudes; moralidade; Alasdair MacIntyre

\section{INTRODUÇÃO, DIAGNÓSTICO DA MORALIDADE MODERNA POR MACINTYRE E ASPECTOS METODOLÓGICOS}

A presente pesquisa tem por objetivo apresentar o conceito de virtude de MacIntyre desenvolvido na obra "After Virtue (1981)" para em seguida refletir sobre as influências dessa base filosófica no instituto da responsabilidade civil, demonstrando que a absorção da ética macintyriana pode implicar: a) no aumento qualitativo na fixação do "quantum" indenizatório; b) no desenvolvimento de outras funções para a responsabilidade civil, diversas da função compensatória, reparatória e punitiva/preventiva e c) no alargamento da incidência da responsabilidade objetiva.

A obra supracitada tem como principais características a crítica da moral na modernidade e a proposta de

\footnotetext{
${ }^{1}$ Pós-doutora em Direito pela Universidade Carlos III de Madri-Espanha. Professora de graduação e de pós-graduação da Universidade Federal do Pará - UFPA e da Universidade da Amazônia - UNAMA. Desembargadora do Tribunal Regional do Trabalho da Oitava Região - TRT8. E-mail: pastoraleal@yahoo.com.com.br

${ }^{2}$ Doutorando em Direito pela Universidade Federal do Pará - UFPA. Professor de graduação e pós-graduação da Universidade da Amazônia - UNAMA. Professor de pós-graduação da Escola Superior da Advocacia - ESA. Professor Orientador da Liga Acadêmica Jurídica do Norte e Nordeste - LAJUPA. Membro da Comissão de Educação Jurídica da OAB/PA. E-mail: alexandrebonna@yahoo.com.br
} 
uma alternativa pautada na ética das virtudes, que possui o seu berço na filosofia grega, em especial na de Aristóteles. O pessimismo de Alasdair MacIntyre em relação à moralidade é tão grande que ele compara a moralidade atual com um cenário fictício assombroso, formado por desastres que fizeram sumir bibliotecas, laboratórios, livros, instrumentos, teorias, universidades, e, nesse momento apocalíptico, há um movimento de alguns cientistas sobreviventes que por meio de sobras de fragmentos parciais tentam explicar a realidade (MACINTYRE, 1981, p. 1):

Assim, Alasdair MacIntyre ilustra como a moral se encontra atomizada, onde as pessoas encontram-se separadas de seus papeis sociais com a perda da noção de dependência na vida do outro e na comunidade como um todo. Ao buscar estabelecer a relação desse mundo fictício com a moralidade, antes de apresentar a sua proposta para reverter esse quadro, Alasdair MacIntyre mostra claramente a sua ojeriza ao caminho ético traçado pela modernidade:

What is the point of constructing this imaginary world inhabited by fictitious pseudoscientists and real, genuine philosophy? The hypothesis which I wish to advance is that in the actual world which we inhabit the language of morality is in the same state of grave disorder as the language of natural science in the imaginary world which I described. (1981, p. 2)

Diante desse quadro, Alasdair MacIntyre diz que há apenas duas saídas teóricas para o dilema moral na contemporaneidade: Nietzsche ou Aristóteles, um em contraposição ao outro, com o diferencial que Nietzsche triunfa diante de todos os teóricos iluministas em diante (berço do desastre moral), porém deixa intacta a tradição das virtudes de Aristóteles, que posteriormente foi retomada por Tomás de Aquino, por não enfrenta-la frontalmente, se ocupando apenas de mostrar as insuficiências do pensamento moderno. Ademais, Alasdair MacIntyre considera que as críticas feitas por Nietzsche não são apenas insuficientes para atingir a tradição aristotélica-tomista, como também acabam sendo vítimas da desordem moral moderna, visto que o modelo de grande homem propugnado por Nietzsche acaba não oferecendo bases racionais para o discurso moral, o que torna a sua teoria tão frágil quanto àquelas que ele tanto criticou:

The problem then is how to construct in an entirely original way, how to invent a new table of what is good and a law, a problem which arises for each individual. This problem would constitute the core of a Nietzschean moral philosophy. For it is in his relentlessly serious pursuit of the problem, not in his frivolous solutions that Nietzsche's greatness lies, the greatness that makes him tbe moral philosopher if the only alternatives to Nietzsche's moral philosophy turn out to be those formulated by the philosophers of the Enlightenment and their successors. (MACINTYRE, 1981, p. 114)

O capítulo 9 da obra "After Virtue" (1981) é intitulado Nietzsche ou Aristóteles e possui o condão de demonstrar que diante do declínio moral, a crítica de Nietzche à modernidade é acertada. Contudo, Nietzche não propõe um discurso moral consistente para substituí-la e não enfrenta às bases da ética das virtudes aristotélicatomista, visto que "Nietzsche does not win the argument by default against the Aristotelian tradition." (MACINTYRE, 1981, p. 258). E, como Nietzche não consegue se desvincular das próprias fraquezas da moral moderna, Alasdair MacIntyre sugere que é preciso recuperar o conteúdo da ética das virtudes, pois tudo será uma 
questão de saber qual o resultado do confronto entre a tradição aristotélica e a liberal individualista moderna, e, caso a ética aristotélica prevaleça diante da tradição liberal, poder-se-á pensar de que modo a ética das virtudes se aplica atualmente:

But it now turns out to be the case that in the end the Nietzschean stance is only one more facet of that very moral culture of which Nietzsche took himself to be an implacable critic. It is therefore after all the case that the crucial moral opposition is between liberal individualism in some version or other and the Aristotelian tradition in some version or other. (1981, p. 259)

Alasdair MacIntyre, então, recomenda um retorno da tradição aristotélica das virtudes, imprimindo e desenvolvendo o seu próprio conceito de virtude de modo a dar sentido à tradição aristotélica perdida, a qual ele considera que oferece a melhor racionalidade teleológica às ações humanas. E, a partir da rejeição às bases da modernidade assentadas nos pensadores iluministas, propõe, calcado na ética das virtudes, o ressurgimento do debate sobre o ambiente comunitário propício para o exercício das virtudes e consequentemente para o fomento da vida boa para o ser humano.

Sob a ótica da presente pesquisa, entende-se que o mesmo diagnóstico feito por Alasdair MacIntyre em relação à moralidade atual é válido para a teoria e prática da responsabilidade civil, pelo que muitas insuficiências constatadas no bojo da responsabilidade civil são decorrentes da falta de um apoio ético. Portanto, o resgate das virtudes pregado pela teoria macintyriana será utilizado para provocar reflexões críticas nas bases teóricas da responsabilidade civil.

\section{A ÉTICA DAS VIRTUDES DE ALASDAIR MACINTYRE}

\section{Que desordens a modernidade produziu na moralidade a ponto de ser necessário resgatar uma tradição perdida?}

As desordens morais produzidas pelo iluminismo geram impactos desastrosos na modernidade, tornando possível a partir do individualismo liberal a coexistência pacífica de setores da vida humana incomunicáveis entre si, mas considerados harmônicos dentro de sua área de abrangência, se perdendo a noção de algum objetivo a ser alcançado em cooperação, tornando inviável o alinhamento a um telos compartilhado.

Em primeiro lugar, a modernidade reflete uma sociedade acentuadamente emotivista, sendo o emotivismo a doutrina que caracteriza todas as avaliações morais como expressões de preferências ou sentimentos (MACINTYRE, 1981, p. 12/13). Nesse sentido, como sobre a ótica emotivista não é possível uma justificação moral racional de validade, vive-se uma sociedade onde discussões morais desaparecem e se acentua uma grave degeneração cultural (MACINTYRE, 1981, p. 12/13)

O indivíduo liberal moderno é desprovido de um telos comunitário, visto que a modernidade produziu a 
ideia de ser humano destacado de seus papeis sociais, o que não havia nas sociedades pré-modernas, onde o sujeito extraia seus deveres e obrigações a partir da sua relação com os diversos grupos sociais, visto que o próprio espaço particular do indivíduo só fazia sentido se estivesse em harmonia com as suas relações sociais (MACINTYRE, 1981, p. 33).

Essa ausência de um telos compartilhado na modernidade é gerada em parte pela existência bifurcada de dois campos abertos de vida: a vida social e a esfera individual: "this bifurcation is itself an important clue to the central characteristics of modem societies" (MACINTYRE, 1981, p. 34). No aspecto individual, os indivíduos são soberanos em suas escolas relacionadas aos bens que desejem perseguir; no tocante à vida social, a burocracia é soberana nessas mesmas escolhas a ser válida para todos como meio de proporcionar a convivência, com legitimidade inclusive para limitar as escolhas arbitrárias e livres dos indivíduos pela lógica burocrática, que também é emotivista e se pauta na "rationality of matching means to ends economically and efficiently." (MACINTYRE, 1981, p. 25)

A modernidade proporcionou a fragmentação da vida do indivíduo, como se fosse possível em termos de moralidade realizar compartimentos de moralidade em detrimento de uma ideia de vida boa para todos, sendo possível o sujeito ocupar diferentes papeis na sociedade onde para cada um desses papeis ele deve desempenhar um conjunto de deveres, mesmo que estes sejam contraditórios, incoerentes e desconexos entre si:

So work is divided from leisure, private life from public, the corporate from the personal. (...) And all these separations have been achieved so that it is the distinctiveness of each and not the unity of the life of the individual (MACINTYRE, 1981, p. 204).

Essa forma atomizada de compreender a vida humana descaracteriza a ideia completa de pessoa, pois a partir do momento que se interpreta os atos humanos em termos de componentes simples e se ignora as histórias e as narrativas que este ser humano faz parte, se reduz a vida a uma sequência de episódios e ações individuais, o que não condiz as práticas sociais socialmente incorporadas. (MACINTYRE, 1981, p. 204)

Outra questão de desordem moral na modernidade é a separação entre o que é moral e o que é jurídico, de modo a reduzir a moralidade ao seio da família e do indivíduo e ampliar o jurídico para a dimensão comunitária. Ao tentar legalizar a moral por meio de standars de comportamento, a modernidade comete um anacronismo com a moral, que não se coaduna com standards fixos universais, ou seja, muitas vezes o jurídico da modernidade não obtem êxito ao regular determinado comportamento com respaldo moral, porque a moralidade só se torna inteligível à luz de uma história e qualquer tentativa tentativa de juridicizar deveres de forma fragmentadada da moral é falha. (MACINTYRE, 1981, p. 55)

Ao se romper com a possibilidade de uma busca compartilhada de bens que vão além de bens individuais e descaracterizar a concepção da natureza histórica do homem, a modernidade produz regras de moralidade ininteligíveis e esvazia de conteúdo ético as regras morais e jurídicas, já que a finalidade da ética é 
capacitar o homem a passar de seu estado atual à dimensão em que o fim é alcançado (MACINTYRE, 1981, p. 52). Assim, ao esvaziar a discussão sobre as virtudes que aproximam o homem desse fim e sobre os vícios que os afastam, a modernidade faz com que, por exemplo, no campo do direito, inúmeros institutos não sejam maximizados em atenção a esse ideal de bem comum compartilhado.

Como para a modernidade o que interessa é que os diferentes papeis sociais cumpram suas regras próprias de maneira atomizada, se perde a arena para o florescimento de virtudes que poderiam auxiliar o homem (ou a comunidade) a sair, por meio de determinadas condutas pautadas em virtudes, do estado real (humannature-as-it-happens-to-be) para um estado ideal a partir do alcance do telos (human-nature-as-it-could-be-ifitrealized-its-telos). Ao se perder essa arena, inúmeras condutas e práticas no bojo de uma sociedade massificada são vistas como líticas e moralmente adequadas simplesmente porque cumprem com as regras de um determinado compartimento normativo (exemplo: contribuinte, empregador, fornecedor) e para a modernidade isso basta. Nessa perspectiva, se retira a chance de avaliar atos humanos como inadequados do ponto de vista ético por estar desafinado com um fim maior que deveria ser buscado independentemente de princípios ou regras juridicizadas, as quais, aliás se revelam carentes de viés teleológico.

O enfraquecimento da noção de uma comunidade com membros dependentes entre si e que pautam sua conduta individual visando a um bem maior do que os individuais gerou o esquecimento do princípio da solidariedade proclamado na Revolução Francesa, sendo inarredável aprofundar a proposta macintyriana de resgate da ética das virtudes como forma de solucionar as desordens morais geradas pela modernidade e compreender de que maneira a tese impacta no instituto da responsabilidade civil.

\section{O resgate das virtudes - os três estágios da vida virtuosa em Macintyre}

A presente pesquisa tem por objetivo refletir sobre o impacto no instituto da responsabilidade civil da solução proposta por Alasdair MaIntyre para a mencionada desordem moral. A tese macintyriana para a saída desse quadro caótico não se revela como "pós-moderna", muito pelo contrário, está calcada nas bases da tradição da ética das virtudes, a qual foi esquecida e abandonada mais claramente a partir do iluminismo.

A tradição que Alasdair MacIntyre tenta recuperar, apesar de ter em Aristóteles o seu maior desenvolvimento, não se resume a ele, tendo sido catalogadas diferentes virtudes também a partir de Homero, Sófocles, Platão, Novo Testamento e Tomas de Aquino. Contudo, acentua Alasdair MacIntyre (1981, p. 169), que todas as concepções de virtudes desapareceram na modernidade: "the plurality of the virtues and their teleological ordering in the good life-as both Plato and Aristotle and beyond them Sophocles and Homer had understood them - disappear".

Essas diferentes concepções de virtudes serviram de base para a empreitada de Alasdair MacIntyre, o 
qual, reconhecendo a impossibilidade de uni-las, porque "they offer us diferente and incompatible lists of the virtues" (MACINTYRE, 1981, p. 181), bem como de utilizá-las por importação automática na atual conjuntura, realizou um confronto entre todas elas e identificou pontos de contato. Esses consensos entre as diferentes concepções de virtudes foram utilizados como elementos teóricos para a construção de uma ideia contemporânea de virtudes.

Essa tarefa só se torna viável para Alasdair MacIntyre porque ele compreende que é possível absorver uma tradição anterior com ressalvas e reformulações (1981, p. 58), sendo coerente a tentativa de resgatar a tradição da ética das virtudes e ao mesmo tempo realizar modificações para se harmonizar com o contexto contemporâneo. É por isso que os três estágios das virtudes em sua teoria podem ser lidos como resultado das imersões às diferentes concepções predecessoras.

Uma das ideias centrais da tradição clássica que embasará o pensamento de Alasdair MacIntyre é a de que as virtudes "are precisely those qualities the possession of which will enable an individual to achieve eudaimonia and the lack of which will frustrate his movement toward that telos" (1981, p. 148). Portanto, existe uma ordem ideal das coisas, e o pleno florescimento humano, o bem-estar e a felicidade no bojo de uma comunidade só será viável através do exercício das virtudes:

For what constitutes the good for man is a complete human life lived at its best, and the exercise of the virtues is a necessary and central part of such a life, not a mere preparatory exercise to secure such a life. We thus cannot characterize the good for man adequately without already having made reference to the virtues. (MACINTYRE, 1981, p. 149)

O conceito de virtude de Alasdair MacIntyre a ser apresentado adiante é complexo e se acenta em três simensões: práticas, unidade narrativa da vida humana e tradição. Essas três etapas representam uma unidade conceitual da tradição da ética das virtudes (1981, p. 186) e devem ser compreendidas como estágios necessários para o alcance de uma vida virtuosa no mundo contemporâneo, com um pequeno cuidado: é condição fundamental para o êxito de um estágio o alcance prévio do estágio anterior. Assim, o terceiro estágio só atinge sua plenitude se os estágios um e dois forem alcançados. Além do mais, os três estágios possuem pontos de contato de modo que cada estágio anterior constitui pilar essencial para o próximo, que aperfeiçoa e desenvolve o precedessor. (MACINTYRE, 1981, p. 181)

\section{Estágio: virtudes e os bens internos das práticas}

A primeira definição de virtude ou a primeira dimensão de uma vida virtuosa está relacionada aos conceitos de práticas e bens internos a essas práticas. Ou seja, é preciso compreender as práticas e os seus bens intrínsecos que uma vez alcançados causam impacto positivo a todos que fazer parte da prática, sendo esta concebida como terreno para a concretização das excelências humanas através do exercício das virtudes e as virtudes serão uma qualidade humana cuja posse e exercício prestigie os bens internos da prática: "a virtue is an 
acquired human quality the possession and exercise of which tends to enable us to achieve those goods which are internal to practices and the Jack of which effictively prevents us from achieving any such goods" (MACINTYRE, 1981, p. 191).

Para compreender o conceito em sua inteireza é fundamental adensar as categorias das práticas e dos seus correlatos bens internos. O conceito de prática de Alasdair MacIntyre pode ser compreendido de forma ampla a ponto de se considerar prática desde o jogo de xadrez, a família e a compra e venda de mercadorias até a comunidade compreendida como um todo e tendo como bem interno o bem comum, o Estado de Direito, as relações de trabalho e de consumo ${ }^{3}$, considerando que prática é qualquer atividade humana complexa, cooperativa, socialmente estabelecida, e que possua bens internos buscados pelos componentes, que representam os padrões de excelência:

(...) any coherent and complex form of socially established cooperative human activity through which goods internal to that form of activity are realized in the course of trying to achieve those standards of excellence which are appropriate to, and partially definitive of, that form of activity, with the result that human powers to achieve excellence, and human conceptions of the ends and goods involved, are systematically extended (MACINTYRE, 1981, p. 187)

E o que pode se entender como bens internos a essas práticas, fundamental para a compreensão do conceito de virtude? São bens que representam os padrões de excelência de uma prática e, uma vez atingidos, beneficiam todos que fazem parte da prática, enquanto que os bens externos ás práticas quando são alcançados se limitam a ser de posse e benefício apenas de uma pessoa ou de um grupo (MACINTYRE, 1981, p. 190).

Importante salientar que Alasdair MacIntyre não está negando às pessoas o direito de auferir lucro e enriquecer, apenas está alertando que do ponto de vista ético poder, fama e dinheiro são bens externos às práticas, mas devem e podem ser conquistados como consequencia secundária pela busca dos bens internos, sob pena de criar um desacordo moral, porque uma prática, em especial a prática da comunidade, deve partilhar uma ideia de bem comum a ser perseguida por todos os membros da prática.

Destarte, visando a sanar eventuais conflitos entre bens internos, Alasdair MacIntyre é cristalino ao afirmar ser inarredável a compreensão hierárquica entre os bens internos assim como um noção de bens que estejam além das práticas, como por exemplo os bens que sustentam as instituições e demais estruturas necessárias para o exercício das virtudes:

\footnotetext{
${ }^{3}$ Há pesquisas que entendem que para MacIntyre as relações de trabalho e de consumo não poderiam ser caracterizadas como práticas visto que os seus componentes estão sempre em busca de bens externos a essas práticas, como dinheiro, poder etc. Nesse sentido: "As atividades laborais de boa parte dos habitantes do mundo moderno não podem ser compreendidas como uma prática nos termos que MacIntyre desenvolve. Pois, ao deslocar o trabalho produtivo de dentro dos laços comunitários, se perdeu a noção de trabalho como uma arte que contribuía para o sustento da comunidade e dos lares. (...) Por conseguinte, as relações meio-fins são necessariamente externas aos fins daqueles que trabalham, e como já ressaltamos, as práticas com bens internos foram excluídas, assim como as artes, as ciências e os jogos são tidos como trabalhos de uma minoria especializada" (SANTOS, 2012, p. $101 / 102)$.
} 
But the goods internal to practices, including the goods internal to the practice of making and sustaining forms of community, need to be ordered and evaluated in some way if we are to assess relative desert. Thus any substantive application of an Aristotelian concept of justice requires an understanding of goods and of the good that goes beyond the multiplicity of goods which inform practices. (...) I have suggested so far that unless there is a telos which transcends the limited goods of practices by constituting the good of a whole human life, the good of a human life conceived as a unity, it will both be the case that a certain subversive arbitrariness will invade the moral life and that we shall be unable to specify the context of certain virtues adequately. (MACINTYRE, 1981, p. 202/203).

Por fim, o exercício das virtudes irá permitir que os bens internos às práticas sejam comtemplados e não nos sejam negados, exigindo um tipo de relacionamento especial entre os participantes, que deverão compartilhar padrões de excelência a serem perquiridos por todos, havendo uma espécie de subordinação mútua entre os mesmos a partir da capacidade de racionalmente classificar esses bens. As virtudes, nessa dimensão, possibilitam uma recompensa comunitária envolvendo todos os participantes.

\section{Estágio: virtudes e a unidade narrativa da vida humana}

O segundo estágio do conceito de virtude está calcado na unidade narrativa da vida humana, porque Alasdair MacIntyre compreende que a consecução dos bens internos às práticas não é suficiente para a plenitude de uma vida virtuosa, e, por isso, entende ser necessário avançar para um estágio que vá além de um contexto particularizado (calcado nas práticas) e alcance um terreno onde se possibilita a referência a um telos de uma vida inteira concebida como uma unidade e avaliada na íntegra: "without an overriding conception of the telos of a whole human life, conceived as a unity, our conception of certain individual virtues has to remain partial and incomplete" (MACINTYRE, 1981, p. 201).

A possibilidade de um telos adequado à uma vida humana avaliada na íntegra não condiz com a modernidade, a qual divide a vida humana em setores distintos com normas próprias e afasta a pessoa de seus papeis sociais, inviabilizando o pensar e o agir arrimado em um telos que compreenda a vida humana como um empreendimento íntegro e uno. Esta compreensão da vida como episódios individuais e isolados não só impedem o terreno fértio para o exercício de virtudes como também é contrária à natureza humana (MACINTYRE, 1981, p. 346).

As ações humanas só se tornam inteligíveis se compreendidas dentro de um processo narrativo, porque o homem é protagonista de sua própria narrativa e coadjuvante na dos outros. Além do mais, a educação moral por meio das narrativas fazem parte do aprendizado nas virtudes e servem de instrumento para que os indivíduos guiem as suas vidas: "Hence there is no way to give us an understanding of any society, including our own, except through the stock of stories which constitute its initial dramatic resources" (MACINTYRE, 1981, p. 216).

Nessa esteira, faz-se necessário compreender a identidade pessoal a partir de um "eu" que possa ser 
avaliado com base na unidade de sua narrativa, que leva em conta os papeis desse eu, os cenários, a sua história e o impacto que desempenha na vida dos demais. Assim, torna-se indispensável para compreender a vida humana que a história do indivíduo está relacionada à história das comunidades que ele pertence e que proporcionaram a identidade pessoal do mesmo:

For the story of my life is always embedded in the story of those communities from which I derive my identity. I am born with a past; and to try to cut myself off from that past, in the individualist mode, is to deform my present relationships. The possession of an historical identity and the possession of a social identity coincide (MACINTYRE, 1981, p. 221).

Como a identidade de uma pessoa e de uma comunidade tem passado, não se pode desvincular do mesmo, sob pena de deformar o papel que devo exercer hoje. A identidade pessoal e a social coincidem, sendo possível alguns tipos de responsabilidade que nada tenham a ver com as paixões, as motivações e as intenções. Essa forma de pensar a responsabilidade muitas vezes frustra o intérprete, naturalmente, por não ser o tipo de responsabilidade corriqueira e habitual:

Quando uma ocorrência é claramente a ação pretendida pelo agente humano, porém não conseguimos identificá-la assim, ficamos tanto intelectual quanto praticamente frustrados. Não sabemos como reagir; não sabemos como explicar; não sabemos nem como caracterizar minimamente como uma ação inteligível. (MACINTYRE, 1981, p. 221)

É possível ser responsável por aquilo que, explícita ou implicitamente, não se optou, porque o indivíduo herdou de sua família, de sua cidade, de sua nação uma séria de patrimônios e expectativas, mas também e principalmente uma quantidade significativa de débitos e obrigações, em relação às quais não se pode ignorar, já que este passado representa o ponto de partida moral do indivíduo: "I inherit from the past of my family, my city, my tribe, my nation, a variety of debts, inheritances, rightful expectations and obligations. These constitute the given of my life, my moral staning point. (MACINTYRE, 1981, p. 220)

Portanto, a identidade pessoal deve ser avaliada dentro de um contexto e cenário, pois somente através deles que as ações se tornam inteligíveis, não sendo possível reputar uma ação episódica e isolada como portadora de virtude ou de vício sem concebê-la como uma unidade narrativa. Um ato isolado deve ser compreendido como parte integrante de uma narrativa para se tornar inteligível, surgindo daí a ideia de ordem narrativa da vida humana. Após dar uma série de exemplos para justificar a unidade narrativa, Alasdair MacIntyre afirma: "In each case the act of utterance become intelligible by finding its place in a narrative." (1981, p. 210)

Nuance enriquecedora na ideia de narrativa é que faz-se parte da sua própria narrativa, mas também da narrativa de outras pessoas, realidade que faz com que seja imanente a esse tipo de ética das virtudes calcada na unidade da vida narrativa que os componentes de uma comunidade tenham o direito de questionar a conduta do outro, já que se interfere na narrativa da vida de todos como personagem coadjuvante, porém, esse tipo de conclusão só é possível se se deixar de analisar a vida como episódios isolados e passá-la a compreendê-la como uma unidade que só se torna inteligível se avaliada na íntegra não só no contexto da narrativa particular do 
indivíduo mas também na narrativa de contextos sociais envoltos numa dada comunidade, como explica Alasdair MacIntyre (1981, p. 218)

The other aspect of narrative selfhood is correlative: I am not only accountable, I am one who can always ask others for an account, who can put others to the question. I am part of their story, as they are part of mine. The narrative of anyone life is part of an interlocking set of narratives. Moreover this asking for and giving of accounts itself plays an important part in constituting narratives

Destaca-se que caracterizar a natureza da vida humana como narrativa não exclui infortúnior, desilusões, tristezas e conflitos. Muito pelo contrário, a maior característica das narrativas é a imprevisibilidade que representa o não saber por onde trilhar. À luz da tese macintyriana, a imprevisibilidade não só é intrínseca às narrativas humanas no contexto particular ou social, como também é necessária, pois é graças a esse momento de angústia e vazio marcado pela ausência de rumo que se torna imprescindível que a comunidade compartilhe de um telos, de alguma imagem de futuro. A característica da imprevisibilidade e o caráter teleológico da estrutura narrativa da vida humana são faces da mesma moeda, como expõe Alasdair MacIntyre:

I argued in Chapter 8 is required by the narrative structure of human life, and the empirical generalizations and explorations which social scientists discover provide a kind of understanding of human life which is perfectly compatible with that structure. (...) This unpredictability coexists with a second crucial characteristic of all lived narratives, a certain teleological character. We live out our lives, both individually and in our relationships with each other, in the light of certain conceptions of a possible shared future (1981, p. 215)

E que bem é esse que deve ser buscado, que esteja além dos bens internos das práticas? A unidade de uma vida humana é a unidade de uma busca narrativa indivisível, então, encontrar esse telos torna indispensável responder a pergunta "O que é o bem para o homem", que será o que todas as respostas à pergunta "O que é o bom pra mim" tem em comum, e, nessa busca, será possível encontrar bens que estejam além das práticas (MACINTYRE, 1981, p. 219).

Nesse modelo de teleologia, é inviável a categorização de bens de maneira prévia, porque a vida boa e o conjunto de virtudes necessárias pra isso estão umbilicalmente ligadas a uma específica identidade social com suas próprias narrativas, motivo pelo qual as virtudes necessárias para a busca desse bem serão aquelas que nos capacitam a entender o que mais é a vida boa para o homem e sustentam as comunidades políticas que permitem que todos possam buscar o bem juntos (MACINTYRE, 1981, p. 219).

\section{3o Estágio: virtudes e tradição}

Considerando que o "eu" carrega consigo uma história e sua identidade pessoal está inserida em um contexto maior comunitário que contribuiu para a sua própria identidade, torna-se consectário lógico que esse "eu" seja portador de uma tradição advinda de gerações anteriores, e, assim como não se pode se desgarram do seu passado e de seus papeis na vida do outro, também não é adequado se esquivar da tradição que se faz parte: "I find 
myself pan of a history and that is generally to say. whether I like it or not, whether I recognize it or not. one of the bearers of a tradition" (MAINTYRE, 1981, p. 221).

Essa próxima dimensão das virtudes visa a sustentar os relacionamentos da comunidade com o passado e com o futuro, e, como se trata do terceiro estágio, pressupõe o êxito dos anteriores relacionados a consecução dos bens internos às práticas e dos bens que estão além das práticas e capacitam a entender o que é a vida boa para o homem (MAINTYRE, 1981, p. 221).

O conceito de tradição para Alasdair MacIntyre, ao contrário de representar o respeito a algo conservador, estático e retrógado, se constitui como algo em ebulição marcado por diversos conflitos e indefinições, porque uma tradição viva (living tradition) incorporada socialmente terá como problemática constante a discussões sobre quais bens fazem parte de tal tradição. Essa tradição que reverbera na comunidade e no indivíduo é primordial para definir quais bens devem ser perseguidos nas práticas e na unidade da vida, porque uma conduta de um indivíduo ou uma prática específica só se tornam inteligíveis a partir da compreensão de que esse indivíduo ou essa prática são parte de uma tradição mais longa e ampla na qual estão inseridos, como destaca Alasdair MacIntyre (1981, p. 222):

(...) the history of a practice in our time is generally and characteristically embedded in and made intelligible in terms of the larger and longer history of the tradition through which the practice in its present form was conveyed to us; the history of each of our own lives is generally and characteristically embedded in and made intelligible in terms of the larger and longer histories of a number of traditions.

Portanto, o conceito completo de virtude necessidade desse terceiro estágio vinculado ao apoio de uma dada tradição, porque é esta que fornece às práticas e às vidas a inteligibilidade, porque ambas fazem partem querendo ou não, de uma tradição mais longa. Sem esse contexto histórico calcado na tradição, arruína-se todo o projeto de uma vida plenamente virtuosa.

Nessa esteira, os vícios que afetam a tradição, consequentemente destroem as práticas e às vidas, porque ambas provêm de uma ou várias tradições. Atento à importância da tradição, Alasdair MacIntyre se preocupa com uma virtude que ele chama de "virtue of having an adequate sense of the traditions to which one belongs or which confront one" (1981, p. 223), relacionada à capacidade de compreender a tradição que se faz parte e de, em momentos de indeterminação, decidir adequadamente em um caso concreto na maior medida em que contemple a tradição.

\section{BASES DA RESPONSABILIDADE CIVIL NO PLANO INTERNO E NO CAMPO DO DIREITO INTERNACIONAL DOS DIREITOS HUMANOS}

A responsabilidade está umbilicalmente ligada à ideia de obrigação, de dever, de modo que o desrespeito, a não observância ou o descaso com esse dever jurídico gera a responsabilização. Portanto, a violação de deveres 
previstos em lei ou em precedentes geram a responsabilização das pessoas físicas ou jurídicas que perpetraram danos injustos.

A partir da identificação da violação da ordem jurídica, classicamente, existem três funções que a responsabilidade civil pode desempenhar. A função reparatória está relacionada à tentativa de estabelecer um valor indenizatório suficiente para conduzir a vítima a um estado tal qual não tivesse sofrido o dano, ou seja, busca, tanto quanto possível, a exata extensão do mesmo ${ }^{4}$, em prestígio ao restitutio in integrum com vistas a pôr a vítima em situação idêntica a de antes do evento danoso, com o conjunto de seus interesses inteiramente preservados.

Esta função busca alcançar em maior grau possível um "valor que em verdade tem para o lesado o bem que se destruiu, ou a perda que sofreu" (MIRANDA, 1958, p. 183), porém, caso não seja possível, pode a responsabilização versar sobre uma prestação equivalente, geralmente em dinheiro, aproximativa, imperfeita, porém frequente em razão dos chamados danos morais, que tem como característica a impossibilidade de pôr a vítima no estado em que se encontrava de modo a retirar todos os males do dano existencial sofrido, cabendo à responsabilidade civil apenas compensar o dano por não se admitir reestabelecimento perfeito do estado anterior.

Já a função punitiva visa a fixar um valor indenizatório maior do que o suficiente para reparar ou compensar o dano sofrido, buscando desestimular o ofensor e consequentemente prevenir a ocorrência de novos danos. Essa forma de fixação de indenização ficou conhecida no direito norte-americano como "punitive damages" e vem sendo objeto de intensas críticas pela suposta ausência de permissivo legal para esta função da responsabilidade civil, contudo, sob a ótica do presente projeto a categoria da indenização punitiva se configura como um importante instrumento de prevenção de danos e proteção da pessoa humana.

Além da identificação da violação da ordem jurídica, tradicionalmente exige-se a culpa, o nexo causal e o dano como pressupostos para a plena caracterização da responsabilização. Especificamente em relação à culpa há um crescente número de hipóteses de responsabilidade objetiva - que prescinde da culpa. A maior de todas as inovações no campo da responsabilidade objetiva se refere à cláusula geral da responsabilidade objetiva pelo risco da atividade, introduzida no ordenamento jurídico brasileiro pelo artigo 927, parágrafo único do Código Civil de 2002 - Lei Federal 10.406/2002 5 , a qual marca a mudança de foco da responsabilidade civil, da pessoa do ofensor e a gravidade de sua conduta para a vítima e o correlato dano injusto sofrido, considerado como tal aquele que resulta da exposição à "atividade de risco".

A responsabilização do dano pelo simples desempenho de uma atividade de risco representa uma resposta aos males de uma sociedade altamente científica e tecnológica, que paradoxalmente não dá conta de

\footnotetext{
${ }^{4}$ O Código Civil de 2002 (Lei Federal 10.406/2002) estabelece, em seu artigo 944, que “a indenização mede-se pela extensão do dano".

${ }^{5}$ Art. 927. Aquele que, por ato ilícito (artigos 186 e 187), causar dano a outrem, fica obrigado a repará-lo.
} 
controlar a produção de danos em massa. Esse paradoxo se instaura pela incapacidade da racionalidade científica de promover instrumentos eficientes e adequados aos riscos da desenfreada produção industrial e de gerir e prever as consequências do risco na sociedade atual, engendrando uma nuvem de insegurança e medo no campo da proteção da pessoa humana.

A incompatibilidade do modelo calcado na culpa com o ideal de respeito à dignidade da pessoa humana ensejou a sua erosão para o fim de proteger o exército de vítimas e evitar o enfrentamento da impossível, extremamente difícil e onerosa demonstração da culpabilidade (LEAL; BONNA, 2013, p. 73/74)

O nexo causal também vem perdendo sua força como elemento para a responsabilização. O nexo de causalidade se caracteriza pela ligação entre o resultado danoso e a conduta perpetrada, de modo que "o dano só pode gerar responsabilidade quando seja possível estabelecer um nexo causal entre ele e o seu autor" (GONÇALVES, 2009, p. 584).

No que tange ao elemento dano, este vem conquistando local de destaque na análise jurisprudencial, como elemento apto, por si só, a atrair a atuação das cortes em amparo às vítimas dos infortúnios mais diversos" (SCHREIBER, 2013, p. 83). Essa constatação traz consigo muitos avanços - como a erosão dos filtros da responsabilidade civil e a correlata potencialização da tutela de vítimas a partir da relativização do peso do nexo causal e da culpa - mas também grandes problemas e desafios, considerando que a identificação das ofensas injustas a bens jurídicos passa a depender da interpretação que se tenha do emaranhado normativo posto à tutela da pessoa humana, destacando-se também o papel dos precedentes judiciais.

Destaca-se que a busca de um fundamento para a tutela de direitos pela teoria da responsabilidade civil não é tarefa simples e ganha dimensão desafiadora em razão do surgimento/reconhecimento de "novos danos" e interesses merecedores de tutela, os quais são viabilizados pela interface do direito civil com o direito constitucional (Constitucionalização do Direito Civil) e a partir do reconhecimento da eficácia dos direitos fundamentais nas relações privadas, considerando que "los poderes privados constituyen hoy una amenaza para el disfrute efectivo de los derechos fundamentales no menos inquietante que la representada por el poder público" (UBILLOS, 1997, p. 243).

Portanto, a importância da ética das virtudes, é profícua a análise de eventual diálogo com a teoria da responsabilidade civil, de modo a enriquecer as reflexões sobre o "quantum" indenizatório, novas funções da responsabilidade civil e extensão da responsabilidade objetiva tendo por base a ética das virtudes.

Parágrafo único. Haverá obrigação de reparar o dano, independentemente de culpa, nos casos especificados em lei, ou quando a vol.11, nº. 02, Rio de Janeiro, 2018.pp. 799- 816 


\section{IMPLICAÇÕES DA ÉTICA MACINTYRIANA NAS BASES TEÓRICAS DA RESPONSABILIDADE CIVIL}

A ética das virtudes apresentada na presente pesquisa possui efeitos na quantificação do dano, especialmente do moral, visto que o valor a ser fixado diante do caso tem como pretensão a compensação do mal sofrido e não o restabelecimento da situação em que se encontrava a vítima. E, nesse desiderato, deve expandir a cognição judicial no sentido de compreender o grau de relevância que determinado bem violado representa na vida do prejudicado.

$\mathrm{Na}$ tarefa de atribuir o valor mais justo apto a compensar o dano sofrido, é salutar que o juiz parta da compreensão da unidade narrativa da vida humana e, no bojo da fase probatória, busque elementos não só que demonstrem a responsabilidade do ofensor, mas também que traga informações suficientes para se compreender o valor que determinado bem possui na vida da vítima de modo a realizar a atividade jurisdicional em nível ético satisfatório, se esquivando da lógica de julgamentos em massa que despersonalizam as partes.

Deve-se partir da ideia de que a pessoa tem a sua vida inserida em inúmeras relações que não foram programadas, passando a figurar como coadjuvante "in media res" na história de outras pessoas, ou seja, faz parte de uma história que sequer foram projetadas no seio de uma vizinhança, de uma família, de uma cidade etecetera, relações essas que tem peso na avaliação do valor necessário para compensar o dano injusto.

Para além disso, uma característica fundamental da narrativa da vida humana é o caráter teleológico, no sentido de que individual ou coletivamente, a vida narrativa tem como base alguma visão de futuro compartilhado, não existindo vida que não esteja projetada para uma meta que sirva de força motriz para mover-se. E, como a vida é destinada a um fim, esse fim pode ser frustrado e arruinado por ato de outrem, sendo imprescindível para um justa fixação da indenização compensatória a investigação desse telos individual que eventualmente tenha sido ofuscado, porque a valor dessa perda pode variar de acordo com a representatividade desse telos na vida individual de cada vítima.

Esse salto qualitativo na fixação do "quantum" é possível a partir do aprofundamento da unidade da vida narrativa e da ideia de que se é personagem da própria vida, coadjuvante na vida de outros, se ingressa sem pretender em um emaranhado de relações sociais e todo esse empreendimento complexo que representa a vida humana deve ser interpretado de forma una e íntegra, tendo sempre em vista o telos que é buscado individual ou coletivamente.

Por esse motivo que a prática judiciária voltada para uma fixação do "quantum" indenizatório de forma automática e repetitiva reafirma o viés da modernidade relacionado à fragmentação da identidade pessoal, que

atividade normalmente desenvolvida pelo autor do dano implicar, por sua natureza, risco para os direitos de outrem. 
insiste em interpretar a vida humana como eventos simples, isolados e episódicos, avaliando o valor dos da indenização compensatória tendo por base apenas os fatos necessários para caracterizar a responsabilidade, porém deixa de lado a investigação de fatos que tornem a vida inteligível.

Outro ponto de impacto da teoria macintyriana na responsabilidade civil se refere ao florescimento de novas funções da responsabilidade civil, diversas da compensatória/reparatória, punitiva/preventiva, como a função que chamarei de "corretiva", que independe da intenção de prevenir danos. Isto se torna possível porque um dos degraus para uma vida virtuosa é a busca por padrões de excelência dentro das práticas por meio da consecução dos bens internos a essas práticas, estágio esse considerado condição "sine qua non" para o êxito de outras dimensões das virtudes.

Percebe-se que as práticas, como qualquer atividade socialmente estabelecida em sentido cooperativo, são cotidianamente corrompidas a ponto de inviabilizar o exercício das virtudes, especialmente no âmbito das relações de trabalho e de consumo, que fomentam um tipo de relação despersonalizada e impessoal, na medida em que os participantes da prática buscam bens externos a elas, como dinheiro e poder.

Considerando que o mundo contemporâneo é marcado por esse tipo de relação jurídica de massa, o alcance dos bens internos dessas práticas é indispensável para que surjam as outras dimensões das virtudes, razoável que se desenvolva uma outra função da responsabilidade civil no sentido de autorizar o juiz a, de ofício, determinar obrigações de fazer, em ações individuais ou coletivas visando a humanizar uma prática específica e proporcionar que os seus componentes busquem os bens internos a essas práticas em um avanço rumo à vida virtuosa.

A responsabilidade civil pode servir de instrumento para lutar contra a patrimonialização das relações humanas e contribuir para que os membros de determinadas práticas compreendam os graus de dependência mutualmente e assimilem a existência de bens que devem ser buscados de forma cooperativa e que uma vez alcançados provocam benefícios para todos os componentes da prática.

Por conseguinte, ao buscar interferir nas estruturas das práticas se fornecerá um ambiente propício para que seja buscado um bem comum e não apenas bens individuais em um empreendimento cooperativo pautado em noções bem definidas sobre o que é uma vida boa e o que são bens que favorecem a todos.

Como exemplo dessa nova função: um fornecedor de instrumentos musicais está como réu em vários processos onde se discute a carência do dever de informação sobre a garantia e funcionamento dos produtos que comercializa. Neste caso, fica prejudicada a prática do bem inerente às relações de compra e venda que é a boa-fé, que impera de forma mais intensa quando se tem a falta do diálogo e de canais de comunicação. Diante do caso em análise, o magistrado pode decidir, com base na função corretiva, impor a obrigação de o réu criar um site ou 
uma ouvidoria de modo a atender os reclamos dos consumidores e fornecer-lhes informações suficientemente, medida esta que não seria possível pelas funções punitiva/preventiva ou compensatória/reparatória.

Por fim, a ética macintyriana também tem impacto no alargamento da responsabilidade objetiva por conta da ideia de que a unidade narrativa da vida humana aduz que todos carregam consigo uma carga histórica, relacionada não só a patrimônio e direitos, mas também a débitos e ônus.

A busca pela unidade narrativa envolve o vínculo inseparável com o passado, presente e futuro, sendo pré-requisito para a inteligibilidade das ações humanas a avaliação na íntegra de toda a carga histórica que uma pessoa carrega consigo, a qual gera no plano ético um tipo especial de responsabilidade, assentada na ideia de que se herda uma carga oriunda inclusive dos relacionamentos predecessores e que só podem ser compreendidos no emaranhado das práticas atuais se as ações e experiências do hoje serem acompanhadas pelo senso que a vincula com o passado.

Essa responsabilidade ética viabilizada pela unidade narrativa torna possível o questionamento mútuo entre pessoas em relação a atos que as afetam, porque se a vida deve ser interpretada a partir da vinculação que possui com o passado e também com as demais pessoas de uma dada prática ou comunidade existe a obrigação de dar satisfações, sob pena de fragmentar a discussão moral e tornar o indivíduo livre de seu passado, de sua história e de seus vínculos nas narrativas de outras pessoas. Assim, a interseção na vida das pessoas através das narrativas atuais e também da herança história que se porta consigo lapidam as discussões sobre a responsabilidade objetiva.

O forte conceito de identidade pessoal em uma narrativa com o peso da identidade cultural e histórica podem gerar, por decorrência lógica da interpretação de uma vida una, o alargamento de hipóteses da responsabilidade objetiva, para além daquelas previstas legalmente a partir do esteio ético porque o conceito de identidade envolve uma dupla tarefa: sou o que sou e também sou o que represento na vida das pessoas independentemente de minhas intenções.

Neste viés, não se pode abstrair o conceito de pessoa de sua história, assim como não se deve atomizar os atos e intenções e esquecer a carga narrativa da vida humana, sendo possível, por exemplo, reputar responsável uma empresa no seguinte exemplo, o que não seria possível dentro das hipóteses legais: em um determinado país a geração de energia foi feita durante 20 anos por uma empresa $X$, a qual entrou em falência, quitou todas as suas dívidas e foi extinta enquanto pessoa jurídica. A empresa $\mathrm{Y}$ assumiu a referida atividade e já está há 10 anos realizando a mesma, quando é surpreendida com uma citação em um processo judicial envolvendo uma criança que quando a empresa $\mathrm{X}$ operava foi vítima de um atropelamento por veículo da empresa $\mathrm{X}$. Por conta do acidente, somente agora se manifestou a necessidade de medicamentos e cirurgias, sendo objeto da ação os danos materiais e morais decorrentes do infortúnio. À luz da tese defendida, a empresa Y deve ser considerada 
responsável pelos danos causados independentemente de suas intenções por ser portadora de uma história segundo a qual os relacionamentos só se sustentam se o presente for indissociável do passado.

\title{
CONCLUSÕES
}

A luta contra a patrimonialização do direito deve ser uma tarefa diuturna de todos os profissionais do direito, os quais podem qualificar esse objetivo a partir da fundamentação da ética das virtudes, posto que qualquer tentativa de compreender o direito sem reflexões de cunho ético, resumem a discussão no plano dogmático e trazem a perigosa possibilidade de se fomentar a legitimidade de decisões que apenas cumprem as exigências legais.

Desta feita, a presente pesquisa considera enriquecedora a interface da responsabilidade civil com a filosofia de Alasdair MacIntyre, podendo ainda ser muito explorada pelos agentes do direito, tendo como norte mas não se limitando - as discussões travadas alhures.

A desordem moral gerada pela modernidade atingiu diversos setores da vida em sociedade e com a aplicação de categorias jurídicas não foi diferente, motivo pelo qual é imperioso o resgate de uma legitimação ética no direito, em todas as suas áreas, visando a ofuscar a fragmentação e atomização da vida humana em setores compartimentados e lutando para o resgate das virtudes, e, por consequência, para uma vida melhor para o homem.

\section{TORT LAW AND ETHICS OF VIRTUES IN THE LIGHT OF ALASDAIR MACINTYRE THOUGHT}

\begin{abstract}
It introduces the concept of virtue to Alasdair MacIntyre in his book "After Virtue" (1981). It develops the problems of moral disorder in modernity. Discusses reasons for the recovery of virtue ethics in the face of atomism and fragmentation of the individual in modernity. Study the three stages of virtuous life to Alasdair MacIntyre, involving practices, unity of human life and tradition. Traces dogmatic aspects of tort law. The main goal is to reflects on the impact of the ethics of Alasdair MacIntyre in the tort law, particularly in the value of the compensatory damages, in the new goals related with strict liability and in the development of new functions of liability. It concludes that the fight against the patrimonialisation of the law must be a diurnal task of all legal professionals, who can qualify this objective from the foundation of the ethics of virtues in the field of tort law.
\end{abstract}

Keywords: Tort Law; Ethics; Virtue; Morality; Alasdair Macintyre 


\section{REFERENCIAS}

LEAL, Pastora do Socorro Teixeira. Responsabilidade civil: inovações normativas, desafios e perspectivas. In: LEAL, Pastora do Socorro Teixeira (coord). Direito Civil-Constitucional e outros estudos em homenagem ao Prof. Zeno Veloso. Método: São Paulo, 2014.

LEAL, Pastora do Socorro Teixeira; BONNA, Alexandre Pereira. Reflexões sobre a cláusula geral da responsabilidade objetiva pelo risco da atividade como mecanismo de concretização do princípio da dignidade da pessoa humana pelo Judiciário. A Leitura: CAD. ESM-PA, Belém, v.6, n. 10, p. 70-83, maio/2013.

MACINTYRE, Alasdair. After Virtue. 3a ed. University of Notre Dame Press: Notre Dame, 1981.

MIRANDA, Pontes de. Tratado de direito privado, Tomo XXII, 2a ed. Rio de Janeiro: Editor Borsoi, 1958.

SANTOS, Lorena Maria de Moura. Comunidade e moralidade na filosofia de Alasdair MacIntyre. Dissertação de Mestrado. Universidade Federal do Piauí: Teresina, 2012.

SCHREIBER, Anderson. Novos paradigmas da responsabilidade civil: da erosão dos filtros da reparação à diluição dos danos. 5a ed. Atlas: São Paulo, 2013.

UBILLOS, Juan María Bilbao. La eficacia de los derechos fundamentales frente a particulares: análisis de la jurisprudencia del tribunal constitucional. Madrid: Centro de Estudios Políticos y Constitucionales, 1997.

Trabalho enviado em 10 de junho de 2017.

Aceito em 01 de novembro de 2017. 